PENANGANAN HASIL TANGKAPAN ALAT TANGKAP PURSE SEINE PADA KM. SINAR HARAPAN - 05 DI PELABUHAN PERIKANAN NUSANTARA (PPN) SIBOLGA

\title{
HANDLING OF PURSE SEINE CAPTURE CATCHING FOR KM. SINAR HARAPAN - 05 IN THE NUSANTARA FISHING PORT (PPN) SIBOLGA
}

\author{
Suci Asrina Ikhsan ${ }^{1 *}$, Muhammad Nur Arkham ${ }^{1}$, Anderson Foresta ${ }^{1}$ \\ ${ }^{1}$ Program Studi Perikanan Tangkap, Politeknik Kelautan dan Perikanan Dumai, Dumai, Riau \\ *Korspondensi: suciaasrinaikhsan@gmail.com
}

\begin{abstract}
The handling of catches on ships in connection with capture fisheries in particular has the aim of preventing or reducing spoilage of fish and the possibility of a decline in the quality of the catch resulting in loss of selling prices. The main causes of the decline in the quality of the catch on the ship there are 5 factors namely how to handle, human resources, facilities, equipment, fishing units. Handling of catches on the ship with the puse seine Tangkap tool in PPN Sibolga based on calculations regarding the imbalance and suitability of the 5 factors handling on the purse seine ship namely handling methods, human resources, facilities, equipment and capture units found that the average value of conformity is by $78 \%$, with the quality management policy in KEPMEN-52A/2013 which is an average of 78\%, handling factors that can be fairly good.
\end{abstract}

Keywords: Handling, Purse Seine, Fishing Port

\section{Pendahuluan}

Provinsi Sumatera Utara dengan panjang garis pantai $1.300 \mathrm{~km}$ dan wilayah Pantai Barat Sumatera yang termasuk dalam wilayah Pengelolaan Perikanan RI (WPP-RI) 572 tercatat memiliki potensi sumber daya perikanan tangkap 1.353.000 ton per tahun. Potensi sumber daya perikanan yang ada di Pantai Barat tersebut sangat besar, baik di perairan teritorial maupun di perairan zona ekonomi eksklusif (ZEE) hingga sejauh 200 mil dari pantai (Bangun, Rosyid dan Boeseno, 2015).

Kota Sibolga merupakan salah satu kota yang memiliki usaha perikanan yang relatif besar dibanding kota-kota lainnya di pantai Barat Sumatera. Di kota ini pengusaha-pengusaha perikanan telah berperan aktif dalam memajukan produksi perikanan lokal, regional bahkan nasional. Peran aktif yang ditunjukkan terlihat dari jumlah dan ukuran armada serta alat tangkap yang dioperasikan relatif lebih besar sehingga menghasilkan produksi yang lebih besar pula. PPN Sibolga memiliki berbagai kelengkapan penunjang aktivitas industri perikanan seperti penanganan hasil tangkapan dan perbaikan alat tangkap (Zain, Syaifuddin dan Aditya, 2011).

Proses penanganan dan penyimpanan hasil tangkapan dikapal merupakan salah satu faktor yang berpengaruh terhadap kualitas hasil tangkapan. Standar penanganan hasil tangkapan telah dijelaskan pada Peraturan Menteri Kelautan dan Perikanan dalam KEPMEN-KP 52A/2013, namun umumnya nelayan kapal purse seine kurang peduli terhadap penanganan hasil tangkapan contohnya mereka masih belum menerapkan aturan yang ada tentang metode penanganan yang baik pada saat diatas kapal. Dampaknya hasil tangkapan yang diharapkan menjadi buruk yang 
mengakibatkan menurunnya kualitas hasil tangkapan. Menurut Litaay dan Pelasula (2019), penyebab menurunnya kualitas hasil tangkapan tidak hanya dilihat dari diatas kapal tetapi juga dilihat dari lingkungan dan sumberdaya manusia. Penelitian ini bertujuan untuk mengetahui tingkat kesesuaian penanganan standar di PPN Sibolga serta mengetahui kualitas hasil tangkapan berdasarkan uji organoleptik.

\section{Metode Penelitian}

Penelitian ini dilaksanakan pada tanggal 11 Maret s/d 29 Juni 2020 yang bertempat di Pelabuhan Perikanan Nusantara (PPN) Sibolga, Provinsi Sumatera Utara. Berikut adalah peta lokasi penelitian:

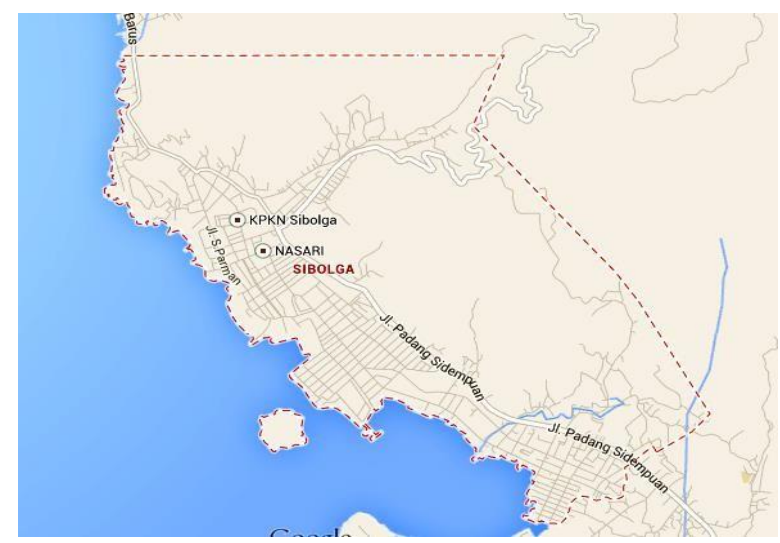

Gambar 1. Peta wilayah Sibolga

Sumber: (BPS Sibolga, 2018)

\section{Metode Pengumpulan Data}

Data yang dikumpulkan merupakan data primer dan observasi. Menurut Mulyadi (2011), data primer adalah data yang mengacu pada informasi yang diperoleh dari tangan pertama oleh peneliti yang berkaitan dengan variabel minat untuk tujuan spesifik studi. Sumber data primer yang dikupulkan melalui observasi dilokasi penelitian, wawancara dan pengisian kuisioner. Data primer digunakan untuk mengetahui tingkat kesesuain terhadap penanganan hasil tangkapan dengan aturan yang telah diterapkan oleh KEPMEN-KP 52A/2013 dimana faktor-faktor penilaian yang sudah tercantum pada KEPMEN-KP 52/A/2013 dan menentukan kualitas hasil tangkapan di atas kapal dan juga pada saat pembongkaran di darat dengan cara uji organoleptik sebanyak 4 orang panelis. Pengamatan sifat organoleptik hasil tangkapan dengan memberikan nilai pada ikan menggunakan score sheet.

Observasi kegiatan penanganan hasil tangkapan dan mengetahui kualitas ikan dilakukan selama penelitian berlangsung. Observasi merupakan salah satu dasar fundamental dari semua metode pengumpulan data dalam peneletian kualitatif, khususnya menyangkut ilmu-ilmu sosial dan perilaku manusia (Hasanah, 2016).

\section{Analisis Data \\ Deskriptif}

Analisis data yang digunakan bersifat deskriptif untuk menganalisa secara 
langsung ketidakseimbangan pada saat penanganan hasil tangkapan di atas kapal sampai setelah didaratkan dengan menggunakan skala likert dengan lembar checksheet penilaian. Dimana menurut Risnita (2012), metode skala likert umumnya digunakan untuk mengukur sikap melalui pertanyaan-pertanyaan yaitu rangkaian kalimat yang mengatakan sesuatu mengenai objek sikap yang hendak diungkap. Pemberian bobot skor dalam penelitian ini adalah sangat baik (SB) dengan bobot skor 5, baik (B) dengan bobot skor 4, cukup baik (CB) dengan bobot skor 3, tidak baik (TB) dengan bobot skor 2 dan sangat tidak baik (STB) dengan bobot skor 1 .

Berdasarkan penilaian yang diperoleh pada saat penanganan hasil tangkapan selanjutnya untuk menghitung faktor cara penanganan hasil tangkapan di kapal purse seine dengan rumus sebagai berikut:

Ketidakseimbangan $=(\mathrm{NSB}-\mathrm{NP})$

Tingkat Kesesuaian $=((\overline{x N S B}) /(\bar{x} \mathrm{NP})) \times 100 \%$

Keterangan:

NSB : Nilai sangat baik dengan bobot skor 5

NP : Nilai yang diperoleh dari penilaian factor terhadap penanganan di atas kapal

$\bar{x} \mathrm{NSB}:$ Rata-rata nilai sangat baik

$\bar{x} \mathrm{NP} \quad$ : Rata-rata nilai hasil penilaian

Adapun keterangan untuk mengetahui ketidakseimbangan penanganan hasil tangkapan di atas pursen seine dengan kriteria $0 \%-\leq 34 \%$ Penanganan sangat tidak baik, $34 \%$ - $\leq 50 \%$ Penanganan tidak baik, 50\% - $\leq 65 \%$ Penanganan cukup baik, $65 \%$ - $\leq 80 \%$ Penanganan baik dan $80 \%$ - $\leq 100 \%$ Penanganan sangat baik

\section{Uji Organoleptik}

Mengetahui kualitas hasil tangkapan dengan cara pengambilan sample menggunakan Simple Random Sampling dengan pengambilan sampel ikan untuk uji organoleptik dilakukan pada 3 jenis ikan yang dominan tertangkap. Pengamatan sifat organoleptik hasil tangkapan dengan memberikan nilai pada ikan menggunakan score sheet. Lembar penilaian ikan segar menggunakan uji organoleptik dapat dilihat pada Tabel 1.

Tabel 1. Lembar penilaian ikan segar

\begin{tabular}{|c|c|c|c|}
\hline No. & Pengamatan & Keadaan & Nilai \\
\hline & Mata & $\begin{array}{l}\text { Bola mata cembung, kornea dan pupil jernih, } \\
\text { mengkilap spesifik jenis ikan }\end{array}$ & 9 \\
\hline & & $\begin{array}{l}\text { - Bola mata rata, kornea dan pupil jernih, agak } \\
\text { mengkilap spesifik jenis ikan }\end{array}$ & 8 \\
\hline & & $\begin{array}{l}\text { - Bola mata rata, kornea agak keruh, pupil agak } \\
\text { keabu-abuan }\end{array}$ & 7 \\
\hline & & $\begin{array}{l}\text { Bola mata agak cekung, kornea agak keruh, } \\
\text { pupil agak keabu-abuan, agak mengkilap } \\
\text { spesifik jenis ikan }\end{array}$ & 6 \\
\hline
\end{tabular}


- $\quad$ Bola mata agak cekung, kornea keruh. pupil 5

agak keabu-abuan, tidak mengkilap

- Bola mata cekung, kornea keruh, pupil keabu- 3

abuan, tidak mengkilap

- Bola mata sangat cekung, kornea sangatkeruh, 1 pupil abu-abu, tidak mengkilap

2. Insang - Warna insang merah tua atau coklat 9

kemerahan, dengan sedikit lendir transparan

- Warna insang merah tua atua coklat 8 kemerahan, kurang cemerlang dengan sedikit

lender transparan

- Warna insang merah muda atau coklat muda 7

dengan sedikit lendir agak keruh

- Warna insang merah muda atau coklat muda 6

dengan lendir agak keruh

- Warna insang merah muda atau coklat muda 5

pucat dengan lendir keruh

- Warna insang abu-abu atau coklat keabuabuan 3 dengan lendir putih susu bergumpal

- Warna insang abu-abu, atau coklat keabuabuan 1 dengan lendir coklat bergumpal

3. Daging - Sayatan daging sangat cemerlang, spesifik 9 jenis, jaringan daging sangat kuat

- Sayatan daging cemerlang spesifik jenis, 8 jaringan daging kuat

- Sayatan daging sedikit kurang cemerlang, 7 jaringan daging kuat

- Sayatan daging sedikit kurang cemerlang, 6 jaringan danging sedikit kurang kuat

- Sayatan daging mulai pudar, jaringan daging 5

kurang kuat

- Sayatan daging kusam, jaringan daging kurang 3

Kuat

- Sayatan daging sangat kusam, jaringan daging 1

Rusak

Sumber: (BSN, SNI 2729, 2013)

\section{Hasil dan Pembahasan \\ Keadaan Umum Kapal Purse Seine}

Pada penelitian ini penulis berkesempatan mengikuti penangkapan ikan dengan alat tangkap purse seine di KM. Sinar Harapan - 05 dengan jumlah awak kapal sebanyak 35 orang. Terdiri dari nahkoda, kepala kamar mesin (KKM), mualim/apit, Serang, oiler, koki dan anak buah kapal (ABK). KM. Sinar Harapan - 05 menggunakan alat tangkap purse seine yang di lengkapi dengan mesin induk, mesin pendingin, dan generator. Kapal ini memiliki desain bentuk kapal V bottom dan system kemudinya manual serta mempunyai kecepatan maksimal \pm 7 knot sehinga lebih mudah untuk berolah gerak pada saat kapal berjalan. Berikut merupakan spesifikasi KM. Sinar Harapan - 05 dapat dilihat pada Tabel 2. 
Tabel 2. Spesifikasi KM. Sinar Harapan - 05

\section{Uraian}

Nama Kapal
Nama Pemilik
Nama Nahkoda
Tanda Selar
Material Kapal
Tahun Pembuatan

Tempat Pembuatan

LOA

\section{Spesifikasi}

KM. Sinar Harapan - 05

Junianto

Muhammad Yusuf

GT.98 No.969/SSd

Kayu dilapisi fyber

1998

Sibolga

$23,52 \mathrm{~m}$

6,24

$2,72 \mathrm{~m}$

$\overline{\text { Adapun spesifikasi mesin pada KM. Sinar Harapan - } 05 \text { dapat dilhat pada Tabel } 3 .}$

Tabel 3. Spesifikasi Mesin KM. Sinar Harapan - 05

\begin{tabular}{ll}
\hline Uraian & Spesifikasi \\
\hline Merk & Nissan Diesel \\
No. Seri & - \\
Daya/PK & $300 \mathrm{PK}$ \\
Bahan Bakar & Solar \\
Sistem Starting & Starter \\
\hline
\end{tabular}

\section{Hasil Tangkapan Purse Seine}

Hasil tangkapan purse seine pada umumnya terdiri dari berbagai jenis ikan pelagis yang suka bergerombol. Hasil tangkapan yang dominan tertangkap di KM. Sinar Harapan - 05 terdiri dari berbagai jenis ikan pelagis yang suka seperti ikan tuna sirip kuning (Thunnus albacore), cakalang (Katsuwonus pelamis) dan serai (Rastrelliger $\mathrm{sp}$ ) .

Tabel 4. Jenis Ikan Hasil Tangkapan KM. Sinar Harapan - 05.

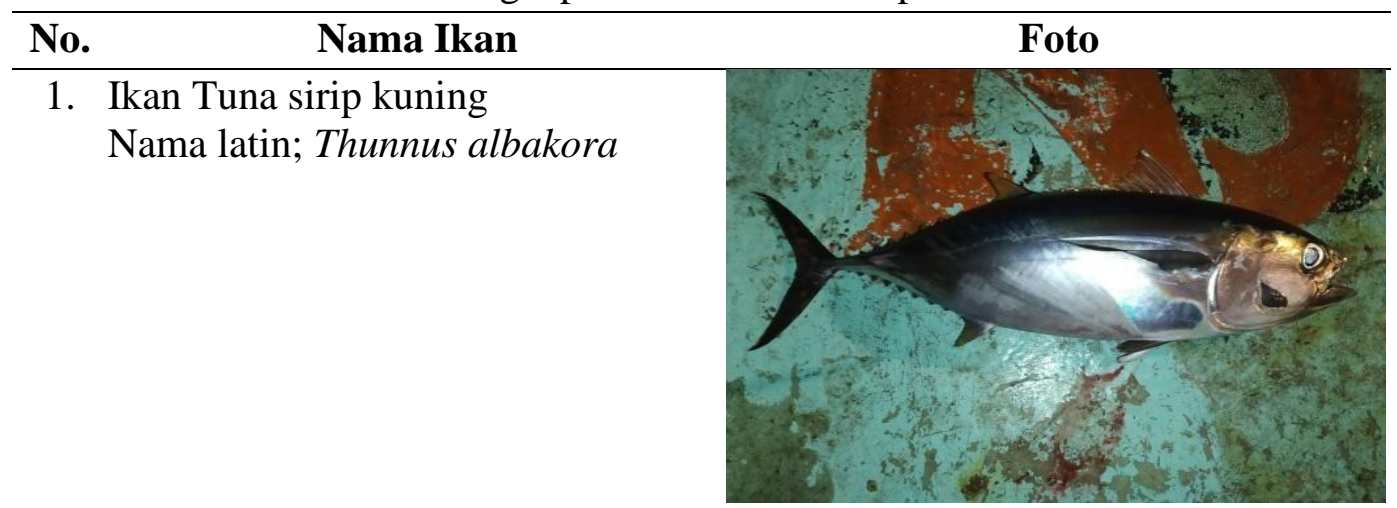


2. Ikan Cakalang

Nama Latin; Katsuwonus pelamis

3. Ikan Serai

Nama Latin; Rastrelliger sp.
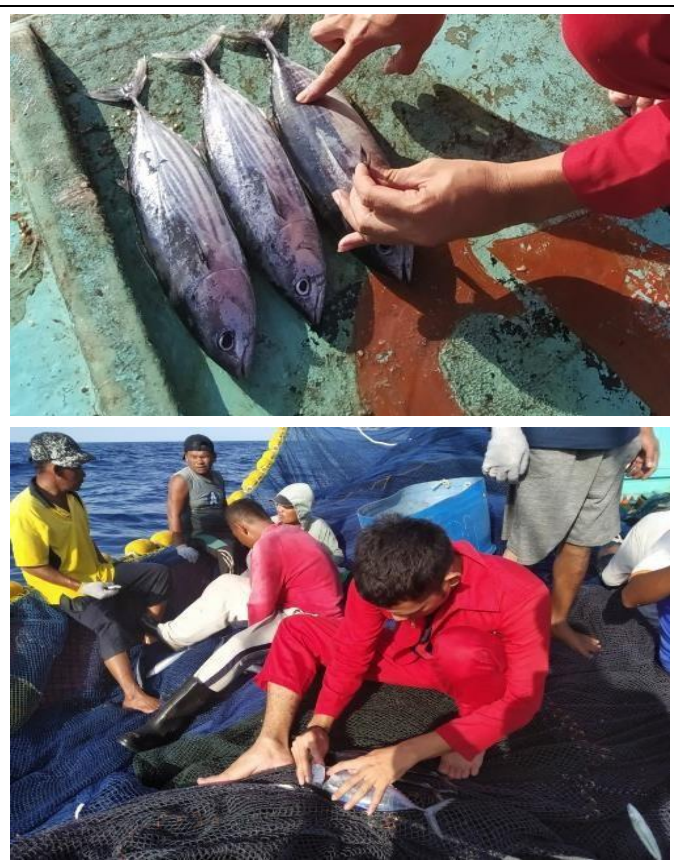

\section{Proses Penanganan di Atas Kapal Purse Seine \\ Pernyotiran Hasil Tangkapan}

Penyortiran dilakukan setelah ikan naik keatas kapal. Penyortiran bertujuan untuk memisahkan jenis dan ukuran ikan agar mudah diatur untuk melakukan penyimpanan kedalam palka. Dimana penyortiran dilakukan oleh BBK dan alat bantu yang di gunakan untuk penyortiran terdiri dari sarung tangan dan kerangjang/blong. Proses penyortiran pada KM. Sinar Harapan - 05 dapat dilihat pada Gambar 3.
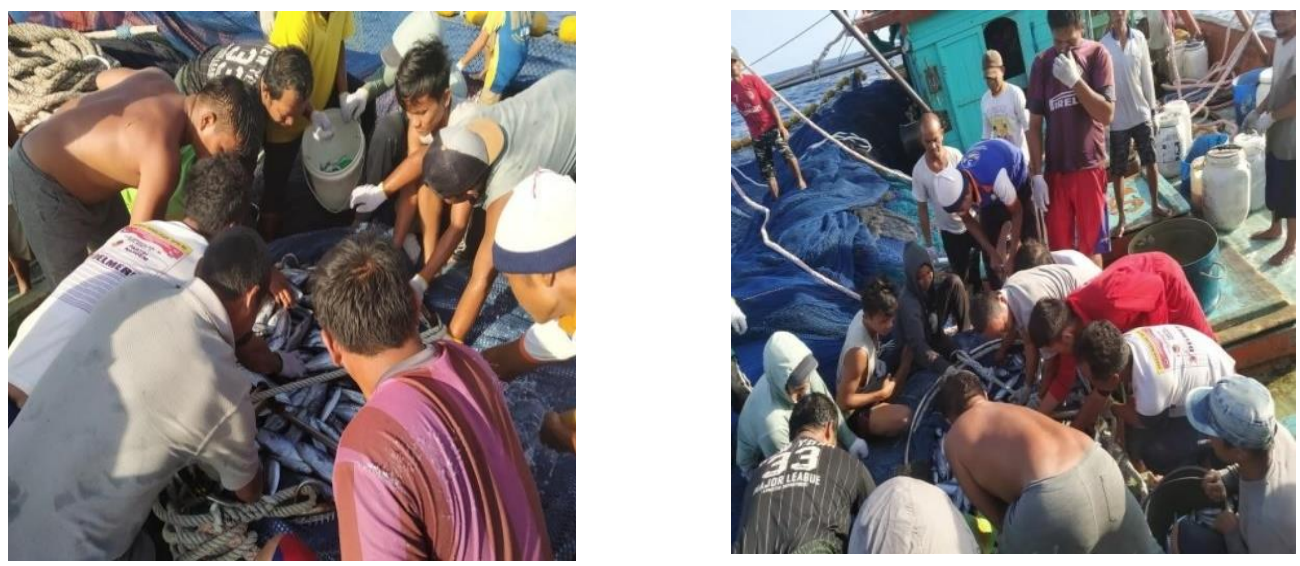

Gambar 3. Proses penyotiran hasil tangkapan KM. Sinar Harapan - 05

\section{Pencucian Hasil Tangkapan}

Pencucian dilakukan setelah ikan selesai disortir. Pencucian hasil tangkapan bertujuan untuk menghilangkan sisik, lendir dan darah pada bagian tubuh ikan. Alat bantu yang digunakan untuk pencucian ikan terdiri dari selang dan mesin pompa air. Dalam pencucian hasil tangkapan di KM. Sinar Harapan - 05 dapat dilhat pada Gambar 4. 


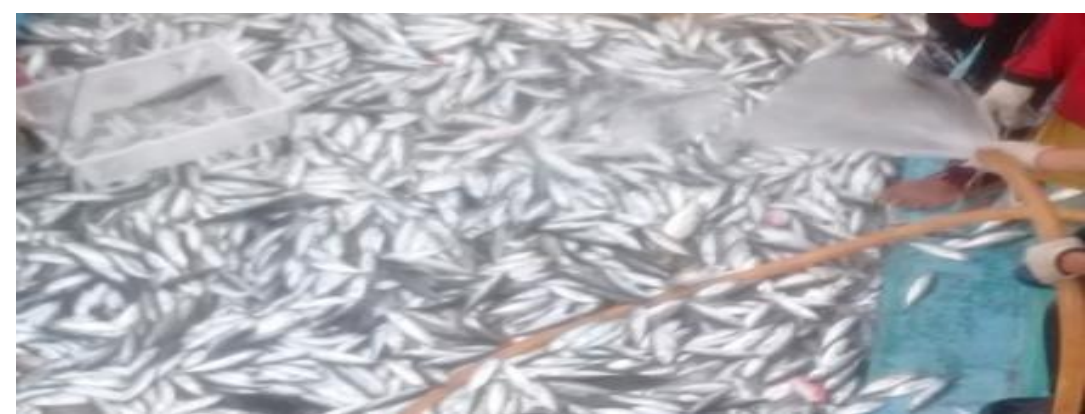

Gambar 4. Pencucian hasil tangkapan KM. Sinar Harapan - 05

\section{Penyimpanan Hasil Tangkapan Kedalam Palka}

Hasil Tangkapan yang telah cuci langsung dimasukkan di dalam palka. Cara penyimpanan ikan di dalam palka dilakukan dengan alat bantu tangguk dan keranjang untuk memasukkan ikan di dalam palka yang telah dilapisi es. Penyimpanan ikan ke dalam palka KM. Sinar Harapan - 05 dapat dilihat pada Gambar 5.

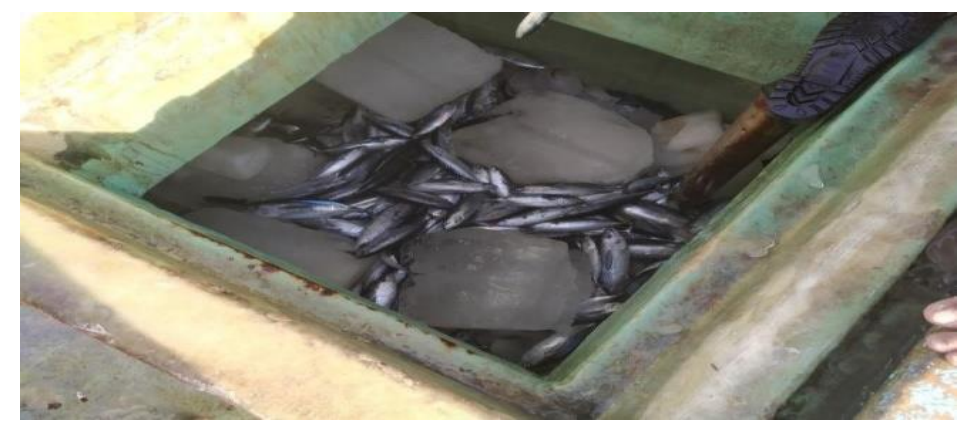

Gambar 5. Penyimpanan ikan ke dalam palka di KM. Sinar Harapan - 05

\section{Tingkat Kesesuaian Penanganan Hasil Tangkapan di atas Kapal}

Berdasarkan analisis data yang didapatkan bahwa terdapat ketidakseimbangan antara penanganan di atas kapal purse seine yang dilakukan KM. Sinar Harapan 05 dengan standar yang berlaku. Hasil perhitungan nilai yang diperoleh dibandingkan dengan nilai standar masih didapatkan ketidakseimbangsan. Adapun hasil penilaian penanganan hasil tangkapan di atas kapal tersebut dapat dilihat sebagai berikut:

Tabel 5. Nilai ketidakseimbangan dan kesesuaian faktor cara penanganan di atas kapal purse seine

\begin{tabular}{|c|c|c|c|c|}
\hline No. & Faktor cara penanganan & NSB & NP & $\mathbf{K S}$ \\
\hline & $\begin{array}{l}\text { Hasil perikanan harus ditangani dan disimpan sehingga } \\
\text { terhindar dari kerusakan fisik apabila penanganan hasil } \\
\text { perikanan menggunakan ganco untuk menangani ikan } \\
\text { besar harus dijaga agar tidak melukai daging ikan. }\end{array}$ & 5 & 4 & 1 \\
\hline & $\begin{array}{l}\text { Hasil perikanan yang tidak disimpan dalam keadaan } \\
\text { hidup harus segera didinginkan setelah naik ke kapal } \\
\text { penangkan dan/atau pengangkutikan. }\end{array}$ & 5 & 5 & 0 \\
\hline
\end{tabular}


3. Melakukan bongkar muat dan pendaratan dengan cepat dan menghindari pembongkaran langsung dibawah sinar matahari.

4. Menempatkan hasil perikanan pada tempat dengan suhu sesuai yang dipersyaratkan.

5. Jika produk perikanan disimpan dalam es, lelehan air es harus tidak menggenangi produk.

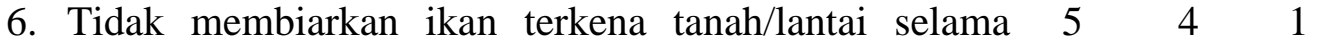
proses pengangkutan.

7. Dilarang menggunakan bahan tambahan yang tidak $5 \quad 5 \quad 0$ diizinkan sesuai ketentuan peraturan perundangan.

8. Ketika suatu produk ikan diketahui tidak baik untuk dikonsumsi maka dipindahkan dan disimpan terpisah dari hasil tangkapan dan ruang kerja penanganan atau dibuang sesuai aturan.

9. Semua produk yang dinilai dapat dikonsumsi segara $\begin{array}{llll}5 & 5 & 0\end{array}$ ditangani dengan baik dengan perhatian penuh untuk tepat waktu srta suhu yang sesuai.

10. Sebelum didinginkan atau disimpan dalam $\begin{array}{lllll}\text { es } & 5 & 1 & 4\end{array}$ dilakukan sortir terlebih dahulu untuk memisahkan sesuai dengan jenis da ukura ikan.

11. Cara penyusunan ikan di dalam palka sesuai dengan jenis $\begin{array}{llll}5 & 1 & 4\end{array}$ mutu dan ukuran ikan.

12. Pemantaun dan pengontrolan waktu, suhu, $\begin{array}{llll}5 & 3 & 2\end{array}$ homogenitas pendinginan dilakikan secara teratur.

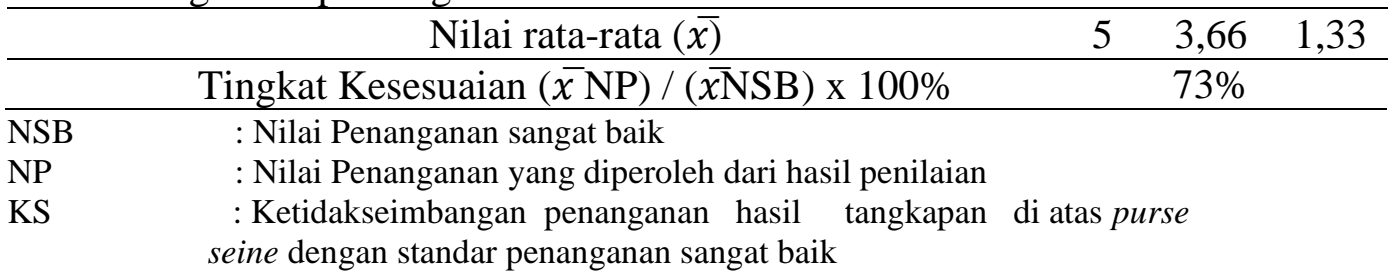

Faktor cara penanganan yang saat ini dilakukan diatas kapal purse seine Sibolga didapatkan ketidakseimbangan sebesar 1,33 (Tabel 5) dengan tingkat kesesuaian yaitu sebesar $73 \%$, yang berarti faktor penanganan diatas kapal purse seine tersebut kurang sesuai dengan standar. Hal-hal yang menyebabkan cara penanganan kurang sesuai dengan standar diantaranya pembongkaran dilakukan dibawah sinar matahari, penempatan ikan pada suhu tinggi serta membiarkan ikan terkena lantai/tanah yang kotor akibat pengangkutan secara manual dengan menggunakan sebilah bambu oleh dua orang petugas sehingga menyebabkan menurunnya mutu hasil tangkapan.

Tabel 6. Nilai ketidakseimbangan dan kesesuaian faktor sumberdaya manusia di atas kapal purse seine

\begin{tabular}{|c|c|c|c|c|}
\hline No. & Faktor sumberdaya manusia & NSB & NP & $\mathbf{K S}$ \\
\hline 1. & $\begin{array}{l}\text { Bekerja dengan hati-hati, hindari perlakuan kasar pada } \\
\text { ikan seperti menyeret, membanting, membengkokkan } \\
\text { dan yang dapat merusak ikan }\end{array}$ & 5 & 3 & 2 \\
\hline
\end{tabular}


2. Semua pekerja sehat saat bekerja, tidak ada yang sedang $\begin{array}{llll}5 & 5 & 0\end{array}$ sakit, sedang mengalami luka tangan, infeksi, atau penyakit menular lain

3. Pekerja yang sedang mengalami luka tangan tidak $\begin{array}{llll}5 & 3 & 2\end{array}$ boleh menangani produk pada setiap proses Penanganan

4. Pekerja yang menangani hasil perikanan mencuci tangan ketika hendak menangani ikan hasil tangkapan pada tiap proses penanganan

5. Tidak diperbolehkan merokok, meludah, makan dan Minum

6. Semua pekerja/ABK bertanggung jawab melindungi $\quad \begin{array}{lll}5 & 3 & 2\end{array}$ ikan dari kontaminasi

7. Pekerja yang menangani ikan memiliki pengetahuan dan $\begin{array}{llll}5 & 3 & 2\end{array}$ keterampilan menangani ikan dan dilakukan secara higienis

8. Semua orang yang bekerja bertanggungjawab $5 \quad 3 \quad 2$ memelihara kebersihan personal, fasilitas proses, kapal, termasuk peralatan dan perlengkapannya

9. Tersedianya alat dan petugas pembersih yang memadai $\quad \begin{array}{llll}5 & 2 & 3\end{array}$ dan mencukupi

10. Tidak diperbolehkan merokok, meludah, makan dan $\quad \begin{array}{lll}5 & 4 & 1\end{array}$ Minum

11. Terdapat program pengawasan secara terus-menerus $\quad \begin{array}{llll}5 & 4 & 1\end{array}$ selama proses pembongkaran ikan

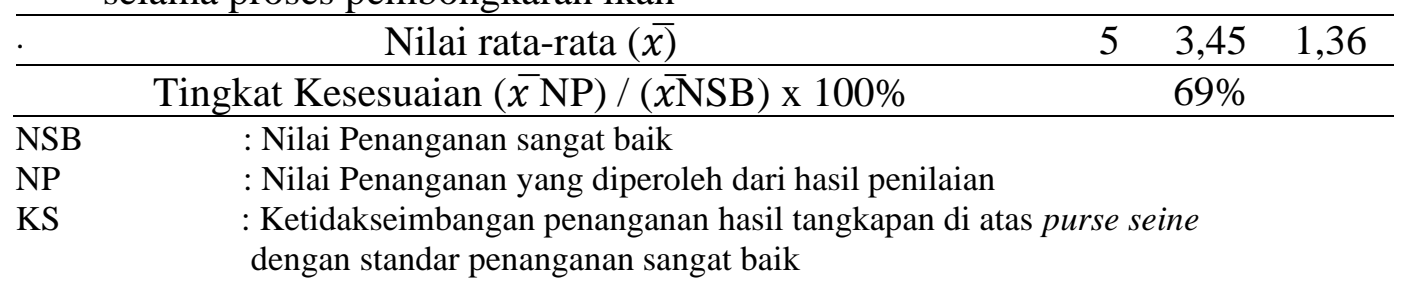

Sumberdaya manusia merupakan salah satu faktor yang kurang sesuai dengan standar karena masih ditemukan ketidakseimbangan yaitu sebesar 1,36 (Tabel 6) dengan tingkat kesesuaian 69\%. Adapun pengaruh yang menyebabkan ketidaksesuaian tersebut diantaranya kurangnya kesadaran nelayan dan pekerja di pelabuhan dalam menjaga mutu hasil tangkapan. Perilaku nelayan dan pekerja di pelabuhan seperti menyeret dan membanting ikan saat proses penanganan berlangsung juga dapat mengakibatkan penurunan mutu hasil tangkapan. Selain itu, kebiasaan nelayan merokok dan meludah sembarangan di area penanganan di atas kapal maupun di pelabuhan juga mengakibatkan terjadinya kontaminasi padaikan.

Tabel 7. Nilai ketidakseimbangan dan kesesuaian faktor fasilitas di atas kapal purse seine

\begin{tabular}{|c|c|c|c|c|}
\hline No. & Faktor fasilitas & NSB & NP & KS \\
\hline & $\begin{array}{l}\text { Tersedia fasilitas pemasaran \& distribusi ikan (TPI, } \\
\text { kendaraan berpendingin, peralatan pemasaran) }\end{array}$ & 5 & 5 & 0 \\
\hline & $\begin{array}{l}\text { Terlindung dan mempunyai dinding yang mudah } \\
\text { untuk dibersihkan }\end{array}$ & 5 & 5 & 0 \\
\hline
\end{tabular}


3. Tersedia pencahayaan yang cukup dan memadai untuk 5 5 50 tiap proses kegiatan

4. Semua permukaan di area penanganan (yang terkena $\begin{array}{lllll}5 & 5 & 0\end{array}$ kontak dengan ikan) berbahan tidak mudah karat, tidak beracun, tahan air dan dalam keadaan baik

5. Konstruksi fasilitas, lantai dilengkapi dengan saluran Pembuangan

6. Jumlah sudut runcing luar pada permukaan dinding area penanganan dibuat seminim mungkin

7. Sistem pendinginan didesain dan diatur untuk 5 4 4 menyediakan pendinginan yang cukup dengan kapasitas penuh sekalipun

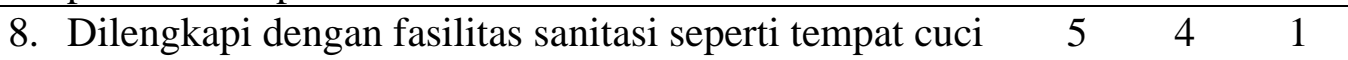
tangan dan toilet dalam jumlah yang mencukupi

$\begin{array}{lllll}\text { 9. Kendaraan yang mengeluarkan asap dan binatang yang } & 5 & 4 & 1\end{array}$ dapat mempengaruhi mutu hasil perikanan tidak diperbolehkan berada dalam area penanganan

10. Fasilitas dilengkapi dengan tanda peringatan dilarang $\quad \begin{array}{llll}5 & 2 & 3\end{array}$ merokok, meludah, makan dan diletakkan di tempat yang mudah dilihat dengan jelas

\begin{tabular}{llccc}
\hline & Nilai rata-rata $(\bar{x})$ & 5 & 4,2 & 1,3 \\
\hline \multicolumn{4}{c}{ Tingkat Kesesuaian $(\overline{\bar{x} \mathrm{NP}}) /(\overline{\mathrm{NNSB}}) \times 100 \%$} & $84 \%$ \\
\hline NSB & : Nilai Penanganan sangat baik & \\
NP & : Nilai Penanganan yang diperoleh dari hasil penilaian \\
KS & : Ketidakseimbangan penanganan hasil tangkapan di atas purse seine \\
& dengan standar penanganan sangat baik
\end{tabular}

Kesesuaian faktor fasilitas yaitu sudah sesuai dengan standar. Hal ini terlihat dari hasil perhitungan nilai ketidakseimbangan yaitu sebesar 1,3 (Tabel 7) dengan tingkat kesesuaian mencapai $84 \%$. Fasilitas penanganan diatas kapal purse seine telah tersedia, namun ada beberapa kebersihan fasilitas juga merupakan masalah yang kurang di perhatikan sehingga ikan muda terkontaminasi.

Tabel 9. Nilai ketidakseimbangan dan kesesuaian faktor peralatan di atas kapal purse seine

\begin{tabular}{lccc}
\hline No. & NSB & NP & KS \\
\hline 1. Wadah yang digunakan terdapat dari bahan yang dapat & 5 & 5 & 0 \\
$\begin{array}{l}\text { melindungi dari kontaminasi } \\
\text { Tersedia kereta dorong untuk memudahkan saat }\end{array}$ & 5 & 5 & 0 \\
$\begin{array}{l}\text { pengangkuatan ikan } \\
\text { Ketersedian es untuk memenuhi kebutuhan melaut dan }\end{array}$ & 5 & 5 & 0 \\
$\begin{array}{l}\text { penanganan pasca penangkapan } \\
\text { 4ir/ea yang digunakan untuk pencucian dan pendinginan } \\
\text { ikan harus memenuhi persyaratan air minum, bersih atau } \\
\text { memenuhi persyratan negara tujuan }\end{array}$ & 5 & 4 & 1 \\
$\begin{array}{l}\text { 5. Bahan peralatan dan semua perlengkapan termasuk } \\
\text { system pengairan harus dipelihara dengan baik }\end{array}$ & 5 & 4 & 1
\end{tabular}


6. Peralatan memindah produk terbuat dari bahan yang $\begin{array}{lllll}5 & 5 & 0\end{array}$ tahan karat yang tidak menularkan bahan beracun dan tidak menyebabkan kontaminasi dan kerusakan pada Ikan

7. Penanganan menggunakan ganco untuk menangani ikan besar dijaga agar tidak melukai daging ikan

8. Peralatan tahan lama mudah dipindahkan serta dapat $\begin{array}{llll}5 & 4 & 1\end{array}$ dipisah-pisah untuk memudahkan pembersiahan, pemeliharaan, disenfektan dan pemantauan

9. Semua peralatan untuk menangani ikan (penangkapan, sortir, grading, pemindahan dan transportasi) bebas kontaminasi dari bahan bakar, air kotor atau lainya

10. Perlengkapan, peralatan serta fasilitas lain harus tetap $\quad \begin{array}{llll}5 & 4 & 1\end{array}$ bersih dalam keadaan baik dan siap pakai

11. Lantai, dinding dan semua peralatan selalu dibersihkan $\begin{array}{llll}5 & 5 & 0\end{array}$ sebelum maupun sesudah bekerja

12. Peralatan pendaratan terbuat dari bahan yang mudah $\quad \begin{array}{llll}5 & 5 & 0\end{array}$ Dibersihkan

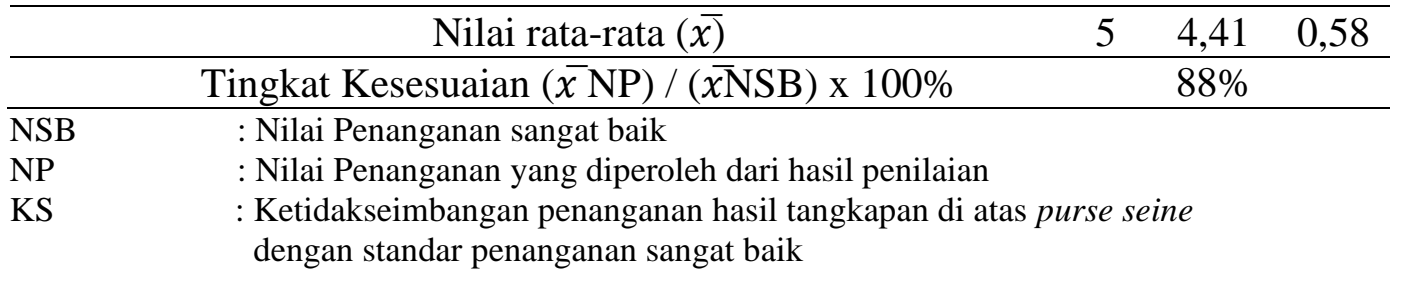

Faktor peralatan didapatkan nilai ketidakseimbangan sebesar 0,58 (Tabel 8) dengan tingkat kesesuaian sebesar $88 \%$, yang berarti faktor peralatan pada saat penanganan sudah sesuai dengan standar.

Tabel 9. Nilai ketidakseimbangan dan kesesuaian faktor unit penangkapan di atas kapal purse seine

\begin{tabular}{lccc}
\hline No. & NSB & NP & KS \\
\hline $\begin{array}{l}\text { 1. Tidak menggunakan teknologi penangkapan ikan yang } \\
\text { dapat merusak fisik ikan }\end{array}$ & 5 & 0 \\
2. & & & \\
Tidak menggunakan alat penangakap ikan yang dapat & 5 & 5 & 0
\end{tabular}

2. Tidak menggunakan alat penangakap ikan yang dapat $\begin{array}{llll}5 & 5 & 0\end{array}$ mempercepat penurunan mutu ikan dan mengakibatkan ikan tersebut terkontaminasi misalkan penangkapan dengan menggunakan racun

3. Kapal penangkap dan pengangkut ikan harus didesain $\quad \begin{array}{lll}5 & 3 & 2\end{array}$ sesuai standar yang ada sehinga tidak menyebabkan kontaminasi terhadap produk dari faktor eksternal antara lain air kotor, limbah, asap, minyak, oli, gemuk dan bahan-bahan lainnya

4. Palka kapal penangkap harus didesain sesuai standar $\begin{array}{lll}5 & 3 & 2\end{array}$ sehingga tidak menyebabkan kontaminasi produk dari jenis material/faktor internal palka (fiberglass, kayu, baja dan lainnya) 
5. Kapal dilengkapi peralatan untuk menjaga kesegaran ikan lebih dari 24 jam harus dilengkapi peralatan palka, tanki atau wadah untuk menyimpan ikan dan menjaga suhu pendinginannya

6. Untuk mencegah kontaminasi palka harus terpisah dari $5 \quad 4 \quad 1$ ruang mesin dan ruang $\mathrm{ABK}$. Palka dan wadah yang digunakan harus menjamin bahwa kondisi penyimpanan dapat menjaga kesegaran ikan dan memenuhi persyaratan higienis

7. Ketika digunakan bagian-bagian dari kapal atau wadah $\quad \begin{array}{lll}5 & 3 & 2\end{array}$ untuk menyimpan hasil tangkap harus dijaga kebersihannya dan dijaga selalu dalam kondisi baik sehinga terhindar dari kontaminasi bahan bakar dan air kotor

\begin{tabular}{|c|c|c|c|}
\hline & Nilai rata-rata $(\bar{x})$ & 3,85 & 1,14 \\
\hline & Tingkat Kesesuaian $(\bar{x} \mathrm{NP}) /(\bar{x} \mathrm{NSB}) \times 100 \%$ & $77 \%$ & \\
\hline NSB & : Nilai Penanganan sangat baik & & \\
\hline NP & : Nilai Penanganan yang diperoleh dari hasil penilaian & & \\
\hline KS & $\begin{array}{l}\text { : Ketidakseimbangan penanganan hasil tangkapan di atas } \\
\text { dengan standar penanganan sangat baik }\end{array}$ & purse seine & \\
\hline
\end{tabular}

Unit penangkapan yang terdiri dari kapal dan alat tangkap didapatkan nilai ketidakseimbangan sebesar 1,14 (Tabel 9) dengan tingkat kesesuaian sebesar 77\%, yang berarti faktor unit penangkapan hampir sesuai dengan standar. Alat tangkap purse seine yang digunakan sangat baik untuk menangkap ikan karena tidak menyebabkan kemunduran mutu hasil tangkapan saat operasi penangkapan berlangsung. Namun, kondisi KM. Sinar Harapan - 05 yang kurang baik yaitu kebersihan dan tata letak ruangnya mengakibatkan ikan terkontaminasi dan mengalami kemunduran mutu.

Tabel 10. Hasil perhitungan kesesuaian faktor penanganan diatas KM. Sinar Harapan - 05

\begin{tabular}{llcccr}
\hline No & \multicolumn{1}{c}{ Faktor } & $\begin{array}{l}\text { Nilai } \\
\text { Standar }\end{array}$ & $\begin{array}{l}\text { Nilai } \\
\text { Penanganan }\end{array}$ & KS & $\begin{array}{c}\text { Kesesuaian } \\
(\%)\end{array}$ \\
\hline 1 & Cara penanganan & 5 & $3,661,33$ & 73 \\
2 & Sumberdaya manusia & 5 & $3,451,36$ & 69 \\
3 & Fasilitas & 5 & $4,21,3$ & 84 \\
4 & Peralatan & 5 & $4,410,58$ & 88 \\
5 & Unit penangkapan & 5 & $3.851,14$ & 77 \\
\hline & Rata-rata kesesuaian & & & 78 \\
\hline
\end{tabular}

Berdasarkan perhitungan mengenai ketidakseimbangan dan kesesuaian terhadap lima faktor penanganan diatas kapal purse seine yaitu cara penanganan, sumberd aya manusia, fasilitas, peralatan dan unit penangkapan didapatkan bahwa nilai rata-rata kesesuaian yaitu sebesar 78\% Tabel (10) dengan kebijakan manajemen mutu yang ada pada KEPMEN-52A/2013 yaitu rata-rata sebesar 78\%. Faktor penanganan yang dapat dibilang cukup baik. 


\section{Pengujian Organoleptik Hasil Tangkapan}

Penilaian organoleptik terhadap hasil tangkapan KM. Sinar Harapan - 05 pada saat penanganan diatas kapal dan pembongkaran dipelabuhan dapat dilihat pada Tabel 11 dan Tabel 12.

Tabel 11. Hasil penilaian organoleptik ikan diatas kapal

\begin{tabular}{|c|c|c|c|}
\hline No. Panelis & Mata & Insang & Daging \\
\hline 1. Anderson Foresta & 9 & 8 & 9 \\
\hline 2. Irvan Jurio & 9 & 9 & 8 \\
\hline 3. Apit & 9 & 8 & 8 \\
\hline 4. Koki & 8 & 9 & 9 \\
\hline Jumlah rata-rata & 8,75 & 8,5 & 8,5 \\
\hline
\end{tabular}

Tabel 12. Hasil penilaian organoleptik ikan pada saat pembongkaran

\begin{tabular}{|c|c|c|c|}
\hline No. Panelis & Mata & Insang & Daging \\
\hline 1. Anderson Foresta & 6 & 7 & 7 \\
\hline 2. Irvan Jurio & 6 & 6 & 7 \\
\hline 3. Apit & 7 & 7 & 6 \\
\hline 4. Koki & 6 & 6 & 7 \\
\hline Jumlah rata-rata & 6,25 & 6,5 & 6,75 \\
\hline
\end{tabular}

Mata

Berdasarkan data tersebut, dapat dilihat bahwa nilai rata-rata organoleptik mata pada penyimpanan diatas kapal adalah nilai 8,75 . Hal ini menunjukkan bahwa pada penyimpanan diatas kapal masih termasuk dalam kategori sangat segar, karena secara organoleptik bola mata masih menonjol, pupil berwarna hitam cerah mengkilap dan kornea selaput mata masih jernih. Pada saat pembongkaran dipelabuhan dari data yang ada menunjukkan bahwa kondisi mata memiliki nilai rata-rata 6,25. Secara organoleptik mata mengalami perubahan yaitu bola mata agak cekung, warna pupil mengalami perubahan warna menjadi keabu-abuan, dan kornea mata menjadi agak keruh. Hal ini menunjukkan bahwa pada penyimpanan secara organoleptik mata mengalami penurunan mutu. Dari hasil analisa organoleptik mata, dapat disimpulkan bahwa semakin lama penyimpanan maka nilai rata-rata organoleptik semakin menurun. Menurut Taher (2010), bahwa salah satu akibat dari mulai berkembangnya bakteri adalah mata jadi terbenam dan pudar sinarnya.

\section{Insang}

Berdasarkan data tersebut dapat dilihat bahwa nilai organoleptik insang pada penyimpanan diatas kapal memiliki nilai rata-rata yaitu nilai 8,5. Dari nilai rata-rata tersebut membuktikan bahwa ikan tersebut masih segar karena insang masih berwarna merah cemerlang, bersih tanpa lendir yang berasal dari bakteri, bau masih segar spesifik dengan jenisnya. Berdasarkan data selama penyimpanan pada saat pembongkaran menunjukkan bahwa kondisi insang memiliki nilai rata-rata 6,5. Secara organoleptik insang mulai timbul kepudaran warna menjadi merah agak 
kusam yaitu dari merah mudah menjadi merah coklat, tampak lendir tebal, bau mulai menusuk dimana bau asam lebih nyata.

Menurut Taher (2010), bahwa ikan yang baru ditangkap mengandung mikroba yang secara alami dimana mikroba tersebut terkonsentrasi pada tiga bagian utama yaitu: permukaan kulit, insang, dan isi perut. Jumlah bakteri pada ikan bervariasi tergantung media dimana bakteri itu hidup, yaitu diantara $10_{2}\left(10_{5} /\right.$ gr pada kulit, $10_{3}$ $\left(10_{5}\right.$ /gr pada insang, dan dapat mencapai $10_{7}$ /gr pada isi perut. Berdasarkan dari data yang ada, maka dapat dikatakan bahwa perubahan warna pada insang itu dapat terjadi akibat peningkatan jumlah bakteri.

\section{Daging}

Berdasarkan data yang ada dapat dilihat bahwa nilai rata-rata organoleptik daging pada penyimpanan diatas kapal mempunyai nilai rata-rata 8,5. Dari nilai rata-rata tersebut dapat dikatakan bahwa pada penyimpanan hasil tangkapan diatas kapal secara organoleptik diging ikan dikategorikan sangat segar karena memiliki tekstur yang masih padat dan kenyal sulit menyobek daging dan tulang belakang. Pada saat pembongkaran di pelabuhan, dari data yang ada memiliki nilai rata-rata daging untuk ikan mempunyai nilai rata-rata 6,75. Dari data tersebut dapat dilihat bahwa secara organoleptik tekstur daging agak lunak, sisik mulai mudah terlepas, tetapi bila ditekan belum ada bekas jari. Menurut Taher (2010) bahwa, perubahan tekstur dimana daging menjadi lebih lunak terjadi apabila ikan sudah mulai mengalami kemunduran mutu. Hal ini disebabkan oleh mulai terjadinya perombakan pada jaringan otot daging oleh proses enzimatis.

\section{Kesimpulan}

Berdasarkan hasil penilitian yang didapat dari lapanga tingkat kesesuaian penanganan hasil tangkapan purse seine di KM. Sinar Harapan - 05 yaitu rata-rata sebesar $78 \%$ yang dapat dibilang penanganan yang baik dan hasil penilaian organoleptik hasil tangkapan KM. Sinar Harapan - 05 pada penyimpanan diatas kapal masih dikategorikan segar sedangkan pada saat pembongkaran dipelabuhan hasil tangkapan mengalami kemunduran mutu.

\section{Daftar Pustaka}

[BPS] Badan Pusat Statistik Kota Sibolga. 2018. Kodisi Geografis dan Iklim Sibolga. sibolga.go.id/kondisi-geografis/. [Internet]. Diakses pada tanggal: [14 Mei 2019].

Badan Standardisasi Nasional. 2013. Ikan Segar. SNI 2729. Jakarta.

Bangun YS, Rosyid A, Boesono H. 2015. Tingkat pemanfaatan dan kebutuhan fasilitas dasar dan fungsional di Pelabuhan Perikanan Nusantara Sibolga Tapanuli Tengah dalam menunjang pengembangan perikanan tangkap. Journal of Fisheries Resources Utilization Management and Technology, 4(1), 12-21.

Hastrini R, Rosyid A, Riyadi PH. 2013. Analisis penanganan (handling) hasil tangkapan kapal purse seine yang didaratkan di Pelabuhan Perikanan Pantai (PPP) Bajomulyo Kabupaten Pati. Jurnal Of Fisheries Utilization and 
Technology, 2(3), 1-10.

Litaay C, Pelasula DD. 2019. Faktor-faktor yang menyebabkan penurunan kualitas cakalang. Jurnal Perikanan dan Ilmu Kelautan, 210-220.

Menteri Kelautan dan Perikanan Republik Indonesia. 2013. No.52A/KEPMEN/KP/2013 Tentang Persyaratan Jaminan Mutu dan Keamanan Hasil Perikanan Pada Proses Produksi. Pengolahan dan Distribusi. Jakarta: DKP.

Taher N. 2010. Penilaian mutu organoleptik ikan mujair (Tilapia mossambica) segar dengan ukuran yang berbeda selama penyimpanan dingin. Jurnal Perikanan dan Kelautan, 6(1), 8-12.

Zain J, Syaifuddin, Aditya Y. 2011. Efisiesi pemanfaatan fasilitas di Tangkahan Perikanan Kota Sibolga. Jurnal Perikanan dan Kelautan,16(1), 1-11. 